\title{
Ovarian cancer: state of the art and perspectives of clinical research
}

Ovarian cancer is composed of three histological subtypes: epithelial (90\%), germ cell (5\%), and sex cord stromal cell (5\%) (1). Epithelial ovarian cancer (EOC) is the most lethal gynecological disorder due to lack of effective early detection strategies (2). The forthcoming special series focuses on several key elements that are essential for an understanding of this heterogeneous group of malignancies.

More than one-fifth of EOC have been related to hereditary conditions (3). Particularly, in about $65-85 \%$ of hereditary ovarian tumors, the genetic abnormality is a germline mutation in breast cancer genes (BRCA) that causes DNA repair defects. Apart from $B R C A 1 / 2$, several other suppressor genes and oncogenes have been associated with hereditary ovarian cancer (i.e., TP53, BARD1, CHEK2, RAD51, and PALB2). Screening efforts are likely to be the best way to detect early stage disease, and germline genetic testing should be offered to EOC patients. The analysis should be able to detect damaging variants in all genes associated to ovarian cancer susceptibility. The complexity of genetic testing increases with the high number of involved genes. Next-generation sequencing (NGS) represents a technology for simultaneous multi-gene analysis, by using very low amount of nucleic acids with rapid turn-around time. However, the incorporation of NGS into clinical practice is for several reasons still challenging. Firstly, the ovarian cancer risk is not clear for some of the included genes. Secondly, variant of uncertain significance rates increase as more genes are analyzed. Finally, beyond germline pathogenic variants, somatic mutations may also affect therapeutic choices, and as such upfront tumor sequencing may be equally important to NGS.

Notch pathway plays a crucial role in ovarian cancer and affects the prognosis. Along with vascular endothelial growth factor (VEGF), it is essential in ovarian cancer angiogenesis, whilst it is also related to chemoresistance. Notch targeting with small-molecule inhibitors or antibodies is a promising treatment in early stage of development. Most important targets for Notch blockade are gamma-secretase and Dll4. Navicixizumab is a bispecific anti-Dll4 and anti-VEGF dual antibody, developed in combination with weekly paclitaxel. Furthermore, xanthohumol and withaferin A had in vitro efficacy through downregulation of Notch1 and Notch3 (4,5).

High-grade serous is the most common histology of EOC. Homologous recombination (HR) is a mechanism of DNA repair important in the carcinogenesis of this subtype. There is mature evidence that poly (ADP-ribose) polymerase (PARP) inhibitors exploit HR deficiency, especially in BRCA1/2 mutants. Indeed, olaparib, rucaparib, and niraparib have been approved by the Food and Drug Administration (FDA) and/or European Medicines Agency (EMA) for the treatment of EOC, while veliparib and talazoparib are in the late stage of clinical development $(6,7)$. Combination of PARP inhibitors with chemotherapy has been recommended with the rationale of disrupting base excision repair via PARP inhibition (8).

In addition, encouraging preliminary results support the therapeutic combination of PARP and immune checkpoint inhibitors (ICI). The input of immunotherapy in ovarian cancer is based on the observation that immunosuppressive microenvironments can affect tumour growth, metastasis, and even treatment resistance (8). Results from ongoing trials demonstrated better outcome of the combined strategy as compared to ICI monotherapy. The definition of optimal predictive biomarkers is essential to optimally identify treatment's candidates.

The standard therapeutic strategy of advanced ovarian cancer is cytoreductive surgery (CRS), followed by systemic chemotherapy. However, neoadjuvant chemotherapy prior to interval debulking surgery could represent an equally effective and even better tolerated alternative. Complete cytoreduction represents the most important clinical endpoint of patients undergoing debulking surgery (9). Unresectability is based on clinical, imaging, and biomarker criteria and guide therapeutic decisions (10). Furthermore, intestinal involvement, extra-pelvic disease, hormone levels and patient's profile are additionally proposed prognostic factors that should be taken into consideration prior to surgical decision $(11,12)$.

Hyperthermic intraperitoneal chemotherapy (HIPEC) becomes nowadays an additional therapeutic strategy for candidate patients (13). The efficacy of HIPEC in combination with CRS is based on the fact that hyperthermia enhances tumor penetration and the cytotoxic effects of chemotherapy. It seems that HIPEC does not increase the mortality and morbidity compared to CRS alone. The latest National Comprehensive Cancer Network (NCCN) guidelines recommend HIPEC at interval cytoreduction (14). HIPEC has been better investigated in the recurrent setting, resulted in improved survival (15). Overall, HIPEC should be offered by highly experienced teams in appropriately selected patients. 
Serous primary peritoneal carcinoma (SPPC) differ from the primary EOC. It is mostly multifocal, characterized by diffuse micronodular spread, resulting in high tumor burden in upper abdomen and diaphragm. The involvement of separate genetic events at different peritoneal loci, differentiates SPPC from EOC with the unifocal nature (16). Immunohistochemically, it is typically positive for CK7, CD15, S-100, P53, WT-1, ER, and PAX-8 and negative for calretinin. Furthermore, SPPC is distinguished from peritoneal mesotheliomas, which are negative for Ber-EP4 and MOC-31 and positive for calretinin and D2-40 (17). The treatment strategy of CRS-HIPEC in patients with primary or recurrent SPPC is still under investigation. The rationale for the HIPEC is the effective regional control of peritoneal carcinomatosis (18).

Treatment with metformin in vitro and in vivo has resulted in decreased angiogenesis in metastatic tissues, probably driven by blockage of the mammalian target of rapamycin (mTOR) signaling pathway (19). Furthermore, metformin targets ALDH+ EOC stem cell populations in vitro, resulting in suppressed angiogenesis, invasion and migration capabilities of EOC cells (20). Regardless the preclinical evidence, results of studies are inconclusive for the association between metformin treatment and survival in EOC patients with type 2 diabetes $(21,22)$.

Patients with endometriosis have an increased risk of EOC, specifically ovarian clear cell carcinoma (OCCC) and endometrioid ovarian carcinoma EnOC (23). Genetic studies provide possible mechanistic link between endometriosis and ovarian cancer. ARID1A mutations coincide with loss of ARID1A protein expression in OCCC (46-57\%) and EnOC (30\%) $(24,25)$. Moreover, conditional homozygous knockout of phosphatase and tensin homolog (PTEN) may drive EnOC. There is also evidence of differential expression of miRNAs in endometriosis and ovarian cancer, mainly linked with epithelialmesenchymal transition (26). Histone deacetyltransferase (HDAC) inhibitors increase the level of acetylated histones, resulting in reactivation of silenced tumor suppressor genes. FDA has already approved the HDAC inhibitors vorinostat, romidepsin, and panobinostat (27).

Non-epithelial ovarian cancers are histologically and clinically distinct uncommon tumors with more favorable prognosis than EOC. The most frequently diagnosed subtypes are the non-epithelial malignant ovarian germ cell tumors (MOGCTs) and the sex cord-stromal cell tumors, subdivided into several histological types (28). Ovarian small cell cancers and sarcomas are rare and biologically aggressive cancers $(1,29)$. MOGCTs typically occur in children and young women, whilst diagnostic challenges in postmenopausal women result in delayed or suboptimal treatment $(28,30)$. Surgical staging remains the cornerstone in the management of MOGTs, and approximately $60-70 \%$ of MOGCTs are diagnosed at stage I.

In this special series, we tried to review the state of the art of the diagnosis and treatment and share future challenges in ovarian cancer, although several areas warrant further research. We would like to express our sincere gratitude to the authors for their efforts, diligence and commitment.

\section{Acknowledgments}

Funding: The authors acknowledge support from the Research and Innovation department of Medway NHS Foundation Trust.

\section{Footnote}

Provenance and Peer Review: This article was commissioned by the editorial office, Annals of Translational Medicine for the series "Ovarian Cancer: State of the Art and Perspectives of Clinical Research". The article did not undergo external peer review.

Conflicts of Interest: Both authors have completed the ICMJE uniform disclosure form (available at http://dx.doi.org/10.21037/ atm-2020-oc-14). The series "Ovarian Cancer: State of the Art and Perspectives of Clinical Research" was commissioned by the editorial office without any funding or sponsorship. SB and NP served as the unpaid Guest Editors of the series. SB serves as an unpaid editorial board member of Annals of Translational Medicine from Nov 2019 to Oct 2021. The authors have no other conflicts of interest to declare.

Ethical Statement: The authors are accountable for all aspects of the work in ensuring that questions related to the accuracy or integrity of any part of the work are appropriately investigated and resolved. 
Open Access Statement: This is an Open Access article distributed in accordance with the Creative Commons AttributionNonCommercial-NoDerivs 4.0 International License (CC BY-NC-ND 4.0), which permits the non-commercial replication and distribution of the article with the strict proviso that no changes or edits are made and the original work is properly cited (including links to both the formal publication through the relevant DOI and the license). See: https://creativecommons.org/ licenses/by-nc-nd/4.0/.

\section{References}

1. Boussios S, Moschetta M, Zarkavelis G, et al. Ovarian Sex-Cord Stromal Tumours and Small Cell Tumours: Pathological, Genetic and Management Aspects. Crit Rev Oncol Hematol 2017;120:43-51.

2. Boussios S, Karathanasi A, Cooke D, et al. PARP Inhibitors in Ovarian Cancer: The Route to "Ithaca". Diagnostics (Basel) 2019;9.pii: E55.

3. Boussios S, Mikropoulos C, Samartzis E, et al. Wise Management of Ovarian Cancer: On the Cutting Edge. J Pers Med 2020;10:E41.

4. Drenzek JG, Seiler NL, Jaskula-Sztul R, et al. Xanthohumol decreases Notch1 expression and cell growth by cell cycle arrest and induction of apoptosis in epithelial ovarian cancer cell lines. Gynecol Oncol 2011;122:396-401.

5. Zhang X, Samadi AK, Roby KF, et al. Inhibition of cell growth and induction of apoptosis in ovarian carcinoma cell lines CaOV3 and SKOV3 by natural withanolide Withaferin A. Gynecol Oncol 2012;124:606-12.

6. Boussios S, Karihtala P, Moschetta M, et al. Veliparib in ovarian cancer: a new synthetically lethal therapeutic approach. Invest New Drugs 2020;38:181-93.

7. Boussios S, Abson C, Moschetta M, et al. Poly (ADP-Ribose) Polymerase Inhibitors: Talazoparib in Ovarian Cancer and Beyond. Drugs R D 2020;20:55-73.

8. Boussios S, Karihtala P, Moschetta M, et al. Combined Strategies with Poly (ADP-Ribose) Polymerase (PARP) Inhibitors for the Treatment of Ovarian Cancer: A Literature Review. Diagnostics (Basel) 2019;9.pii: E87.

9. du Bois A, Reuss A, Pujade-Lauraine E, et al. Role of surgical outcome as prognostic factor in advanced epithelial ovarian cancer: a combined exploratory analysis of 3 prospectively randomized phase 3 multicenter trials: by the Arbeitsgemeinschaft Gynaekologische Onkologie Studiengruppe Ovarialkarzinom (AGO-OVAR) and the Groupe d'Investigateurs Nationaux Pour les Etudes des Cancers de l'Ovaire (GINECO). Cancer 2009;115:1234-44.

10. Vergote I, du Bois A, Amant F, et al. Neoadjuvant chemotherapy in advanced ovarian cancer: On what do we agree and disagree? Gynecol Oncol 2013;128:6-11.

11. Clifford C, Vitkin N, Nersesian S, et al. Multi-omics in high-grade serous ovarian cancer: Biomarkers from genome to the immunome. Am J Reprod Immunol 2018;80:e12975.

12. van Zyl B, Tang D, Bowden NA. Biomarkers of platinum resistance in ovarian cancer: What can we use to improve treatment. Endocr Relat Cancer 2018;25:R303-18.

13. Rufián S, Muñoz-Casares FC, Briceño J, et al. Radical surgery-peritonectomy and intraoperative intraperitoneal chemotherapy for the treatment of peritoneal carcinomatosis in recurrent or primary ovarian cancer. J Surg Oncol 2006;94:316-24.

14. Armstrong DK, Alvarez RD, Bakkum-Gamez JN, et al. NCCN guidelines insights: ovarian cancer, version 1.2019. J Natl Compr Canc Netw 2019;17:896-909.

15. Hotouras A, Desai D, Bhan C, et al. Heated intraperitoneal chemotherapy (HIPEC) for patients with recurrent ovarian cancer: a systematic literature review. Int J Gynecol Cancer 2016;26:661-70.

16. Huang LW, Garrett AP, Muto MG, et al. Identification of a novel $9 \mathrm{cM}$ deletion unit on chromosome 6q23-24 in papillary serous carcinoma of the peritoneum. Hum Pathol 2000;31:367-73.

17. Boussios S, Moschetta M, Karathanasi A, et al. Malignant peritoneal mesothelioma: clinical aspects, and therapeutic perspectives. Ann Gastroenterol 2018;31:659-69.

18. Yuan J, He L, Han B, et al. Long-term survival of high-grade primary peritoneal papillary serous adenocarcinoma: a case report and literature review. World J Surg Oncol 2017;15:76.

19. Erices R, Cubillos S, Aravena R, et al. Diabetic Concentrations of Metformin Inhibit Platelet-Mediated Ovarian Cancer Cell Progression. Oncotarget 2017;8:20865-80. 
20. Shank JJ, Yang K, Ghannam J, et al. Metformin Targets Ovarian Cancer Stem Cells in Vitro and in Vivo. Gynecol Oncol 2012;127:390-7.

21. Urpilainen E, Marttila M, Hautakoski A, et al. Prognosis of Ovarian Cancer in Women With Type 2 Diabetes Using Metformin and Other Forms of Antidiabetic Medication or Statins: A Retrospective Cohort Study. BMC Cancer 2018;18:767.

22. Garcia C, Yao A, Camacho F, et al. A SEER-Medicare Analysis of the Impact of Metformin on Overall Survival in Ovarian Cancer. Gynecol Oncol 2017;146:346-50.

23. Robinson KA, Menias CO, Chen L, et al. Understanding Malignant Transformation of Endometriosis: Imaging Features With Pathologic Correlation. Abdom Radiol (NY) 2020;45:1762-75.

24. Wiegand KC, Shah SP, Al-Agha OM, et al. ARID1A Mutations in Endometriosis-Associated Ovarian Carcinomas. N Engl J Med 2010;363:1532-43.

25. Jones S, Wang TL, Shih IM, et al. Frequent Mutations of Chromatin Remodeling Gene ARID1A in Ovarian Clear Cell Carcinoma. Science 2010;330:228-31.

26. Braicu OL, Budisan L, Buiga R, et al. miRNA Expression Profiling in Formalin-Fixed Paraffin-Embedded Endometriosis and Ovarian Cancer Samples. Onco Targets Ther 2017;10:4225-38.

27. Yang Q, Yang Y, Zhou N, et al. Epigenetics in Ovarian Cancer: Premise, Properties, and Perspectives. Mol Cancer 2018;17:109.

28. Boussios S, Zarkavelis G, Seraj E, et al. Non-epithelial Ovarian Cancer: Elucidating Uncommon Gynaecological Malignancies. Anticancer Res. 2016;36:5031-42.

29. Boussios S, Karathanasi A, Zakynthinakis-Kyriakou N, et al. Ovarian Carcinosarcoma: Current Developments and Future Perspectives. Crit Rev Oncol Hematol 2019;134:46-55.

30. Boussios S, Attygalle A, Hazell S, et al. Malignant Ovarian Germ Cell Tumors in Postmenopausal Patients: The Royal Marsden Experience and Literature Review. Anticancer Res 2015;35:6713-22.

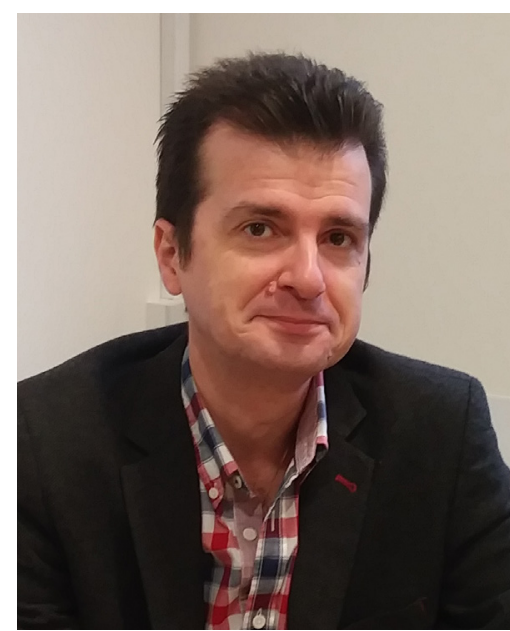

Stergios Boussios

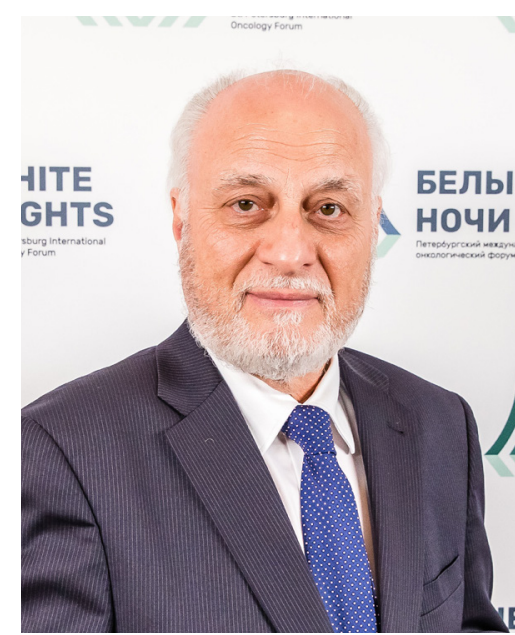

Nicholas Pavlidis 
Stergios Boussios ${ }^{1,2}, \mathrm{MD}, \mathrm{PhD}, \mathrm{MRCP}$ (London)

${ }^{1}$ Department of Medical Oncology, Medway NHS Foundation Trust, Windmill Road, ME7 5NY, Gillingbam, Kent, UK; ${ }^{2}$ AELIA

Organization, 9th Km Thessaloniki - Thermi, 57001, Thessaloniki, Greece.

(Email:stergiosboussios@gmail.com; stergios.boussios@nbs.net)

Nicholas Pavlidis ${ }^{3}$

${ }^{3}$ Medical School, University of Ioannina, Stavros Niarchou Avenue, 45110, Ioannina, Greece.

Submitted Jul 20, 2020. Accepted for publication Aug 05, 2020. doi: $10.21037 / \mathrm{atm}-2020-\mathrm{oc}-14$

View this article at: http://dx.doi.org/10.21037/atm-2020-oc-14

Cite this article as: Boussios S, Pavlidis N. Ovarian cancer: state of the art and perspectives of clinical research. Ann Transl Med 2020;8(24):1702. doi: 10.21037/atm-2020-oc-14 